\title{
The British Journal of Dermatology.
}

September 1913.

Bunch, J. L. Hereditäre Dupuytrensche Kon-
traktur. p. 279.
Die Arbeit von Bunch enthält einen bemerkenswerten Beitrag zur Kenntnis der Mendelschen Vererbungsregeln. Es handelt sich um eine Familie, in der die Dupuytrensche Fingerkontraktur seit dreihundert Jahren erblich ist und zwar wird die Anomalie nur von den männlichen Mitgliedern übertragen und nur die männlichen Mitglieder der Familie sind affiziert. Dieser Übertragungsmodus differiert also von dem bei der progressiven Muskelatrophie, bei der Friedreichschen Ataxie und bei der Hämophilie. Immer beginnt die Affektion in demselben Alter und $\mathrm{zwar}$ an beiden Händen und erreicht ibr Maximum in demselben Alter. Die Beschäftigung spielt gar keine Rolle, denn die Affizierten wiesen die heterogensten Berufe auf. Zur Zeit weisen Großvater, Vater und Enkel die Anomalie auf. Das erste Symptom ist immer eine kleine Kurvatur des kleinen Fingers, die während der ersten 5 Lebensjahre sich ausbildet. Im Alter von 25 Jahren sind die kleinen Finger gebeugt und am Ringfinger beginnt dieselbe Kontraktur, bis im Alter von etwa 35 Jahren eine Beugung dieses Fingers im rechten Winkel besteht. Der Vater ist 50 Jahre alt; seit mehr als 10 Jahren hat die Krankheit keine Fortschritte gemacht. Der dreijährige Enkel zeigt die beginnende Beugung der kleinen Finger.

Fritz Julius berg (Posen).

\section{The Journal of cutan. diseas. incl. Syph.}

\author{
XXXI. September 1913. Nr. 9.
}

Towle, Harvey Parker. Über selbstverursachte Ausschläge. p. 611 .

Man kann die hieher gehörigen Fälle in zwei Gruppen teilen. In die erste kann man alle stellen, bei welchen die Selbstbeschädigung erwiesene Tatsache ist. Für die Fälle der zweiten Gruppe jedoch, welche morphologisch von jenen der ersten nicht zu unterscheiden sind, ist nur das sicher, daß sie mit Hysterie verbunden sind; das tatsächlich veranlassende Moment, das Motiv, ist noch nicht entdeckt. Das Studium der Hysterie als eines psychischen Vorganges gibt aber genügend Handhaben für eine Erklärung des bisher unbekannten Motivs.

Bowen, John T,, Boston. Hochgradige Bronzefärbung mit Hautgeschwïlsten in einem Falle bösartigen Lymphoms (Hodgkins Erkrankung). p. 613. 